\title{
RELAÇÃO AMOROSA E TENTATIVA DE SUICÍDIO NA ADOLESCÊNCIA: UMA QUESTÃO DE (DES)AMOR
}

\author{
love-Based Relationhip and Suicide Attempt in Adolescence: a Matter of (Un)Love
}

Relación de Amor y Intentos de Suicidio en la Adolescencia: una Cuestión de (Des)Amor

Ana Karina Silva Azevedo

Elza Maria do SOCORro Dutra

\begin{abstract}
Resumo: O objetivo desta pesquisa consistiu em compreender como adolescentes que tentaram suicídio por questões amorosas vivenciaram essa experiência. Para tanto, adotamos como referencial teórico o construto self, segundo o pensamento de Carl Rogers. A estratégia metodológica utilizada teve inspiração humanista-existencial, utilizando como instrumento de pesquisa a narrativa, baseada nas idéias de Walter Benjamim (1994). Participaram do presente estudo quatro jovens (três do sexo feminino e um do sexo masculino). O estudo evidenciou a presença de impulsividade com relação ao ato suicida; a maioria dos jovens era proveniente de famílias que vivenciaram a perda de uma das figuras parentais, ou separação dos pais. A tentativa de suicídio foi cometida através da ingestão de medicamentos; observamos também a expressão de culpa ou arrependimento após a tentativa de auto-extermínio. Em relação ao autoconceito desses jovens, observamos a presença de baixa auto-estima, com visões distorcidas de si. Fatores como o contexto familiar, a educação, os valores cultivados socialmente e os aspectos culturais de nossa sociedade influenciaram a maneira como os adolescentes de nossa pesquisa se percebiam. Os resultados confirmam a importância de se perceber a tentativa de suicídio como um fenômeno multideterminado.
\end{abstract}

Palavras-chave: Relação amorosa; Adolescência; Tentativa de suicídio; Pesquisa humanista.

Abstract: This research objective was to understand how adolescents who have attempted suicide because of love-related reasons have gone through this experience. The theoretical reference for the research was the construct 'self', according to Carl Rogers. The methodological strategy was inspired by the existential-humistic strategy. It used the narrative as a research instrument, inspired by the work of Walter Benjamim (1994). The study detected, among the adolescents who were interviewed, the existence of impulsiveness related to the suicide attempt. Also, the majority of the interviewees came from family who had lost of one of their parents or had to face their parents divorce. The suicide was attempted by these youngsters through the ingestion of medicines. The research also revealed that the youngsters had regretted attempting suicide and felt guilty about it. With regards to their self-evaluation, the author observed that the youngsters had low self-esteem, negative perceptions about themselves and distorted views of themselves. These findings helped the author to reflect on the close relationship between the construct 'self' and the suicide attempt. This study contributed to the analysis and reflection on the factors that contribute to suicide attempts.

Keywords: Love; Adolescence; Suicide attempt; Humanistic research.

Resumen: Esta investigación tuvo como objetivo comprender cómo los adolescentes que han intentado suicidarse por razones experimentadores de amor. El estudio, de lo teórico como terapia centrada en el cliente, la construcción del yo, de acuerdo al pensamiento de Carl Rogers. El enfoque metodológico se inspiró existencial-humanista, utilizando como una herramienta para buscar en el relato, inspirado en Walter Benjamin (1994). El estudio mostró, entre los adolescentes, la presencia de la impulsividad en relación con el acto suicida, la mayoría son de familias con la pérdida de los padres o la separación de los padres. El intento de suicidio fue cometido por jóvenes a través de la ingestión de drogas, también observamos la expresión de culpa o arrepentimiento después de intentar auto-exterminio. En cuanto a autoconcepto de los jóvenes, observó la presencia de una baja autoestima, con atribuciones negativas sobre sí mismos y visiones distorsionadas de sí mismos, lo que nos permitió reflexionar sobre la estrecha relación entre el constructo suicidio auto e intentó. El estudio motivado la reflexión sobre los resultados, contribuyendo así al desarrollo de acciones preventivas, que pueden ser efectuados en concepto de subsidios para los programas y políticas de salud pública.

Palabras-clave: Relación amorosa; Adolescência; Intento de suicidio; Investigación fenomenológica.

\section{Introdução}

A tentativa de suicídio entre adolescentes é um dado presente em estatísticas nos estudos desse fenômeno, as quais têm revelado o crescente número de suicídios nessa faixa etária, como visto em pesquisas como a de Souza, Minayo \& Malaquias (2002). O estudo constatou que, de 1979 a 1998, em Belém, Fortaleza, Natal, Recife, Salvador, Belo Horizonte, Vitória, Rio de Janeiro, São Paulo (capital), Curitiba e Porto Alegre, houve um aumento de $42,8 \%$ 
no número de suicídios entre jovens de 15 a 24 anos. No Rio Grande do Norte, em pesquisa realizada por Dutra (1997), entre os anos de 1985 a 1996 ocorreram 567 suicídios, dentre os quais 152 eram de jovens com idade compreendida entre 10 e 24 anos, representando $26,8 \%$ das taxas obtidas no período estudado. No índice de suicídio apontado por esta pesquisa, evidencia-se um aumento de mais de $600 \%$ de suicídio de jovens, tendo em vista que, em 1985, foram registrados apenas três casos nessa faixa etária, enquanto no ano de 1996 registraram-se 29 casos de auto-extermínio entre jovens da referida faixa etária, representando um aumento bastante significativo.

O suicídio é um fenômeno presente em todas as civilizações, adquirindo, assim, diferentes significados, de acordo com cada cultura. O que dizer, então, da tentativa de suicídio de um adolescente por motivos amorosos? $\mathrm{O}$ outro amado seria capaz de motivar o desejo de desistir de viver? Isso nos faz pensar acerca da forma como o amor se expressa entre os adolescentes, podendo tornar-se um motivo ou razão para que se desista de viver.

Autores como Dias (1991b), Dutra (2000) e Mustelier (2005), pensam que a questão amorosa, representada pela perda ou separação do outro amado, é um dos motivos presentes na tentativa e/ou no suicídio exitoso. Por exemplo, o fim de um relacionamento amoroso, o desprezo do ser amado ou até mesmo a ameaça de abandono por parte deste. Assim, este artigo pretende refletir sobre a experiência de ser adolescente nos dias atuais, sobre a experiência de amar na adolescência e, sobretudo, acerca da finitude, revelada na tentativa de abrir mão da própria vida. Com base em tais reflexões, o nosso objetivo consiste em compreender como adolescentes que tentaram suicídio por questões amorosas vivenciaram essa experiência.

\section{Adolescente ou Adolescência?}

Encontramos definições diversas do que significa ser adolescente e tal multiplicidade de conceitos representa e reflete a maneira como lidamos com os jovens: ora tentamos entender cada processo do adolescer como algo único, ora tentamos estabelecer comparações e enquadrálos em uma categoria geral. Cada adolescente é único e vive a adolescência de maneira singular. Para alguns, tal momento é conturbado, repleto de questionamentos, de mudanças físicas, de perda de referenciais, bem como de adoção de novas referências no mundo. Para outros, é apenas uma etapa da vida, como qualquer outra, em que acontecem mudanças, pelas quais é importante passar. Alguns se rebelam, outros se aquietam. O que queremos dizer com toda essa gama de possibilidades de ser é que a adolescência é uma construção única. E é a partir dessa concepção que percebemos o modo de ser adolescente. Ressaltamos que, quando nos referimos à adolescência neste artigo, não a estamos considerando como um fenômeno universal, que se apresenta da mesma forma em qualquer cultura ou lugar; ao invés disso, estamos sugerindo que essa etapa do desenvolvimento se apresenta de forma singular em cada indivíduo, estando relacionada à maneira como o sujeito existe no mundo, e como se relaciona com o contexto social e histórico que constituem o ser no mundo.

Assim como Palácios (1995), pensamos que é melhor falar de adolescentes do que de adolescência, e qualquer fenômeno a ser avaliado deve levar em conta a perspectiva da história evolutiva do sujeito e suas características no conjunto de sua vida. Isso chama a atenção para o fato de que essa fase do desenvolvimento deve ser entendida como um fenômeno psicossocial; ou seja, deve ser compreendida a partir da história individual de cada sujeito e do contexto social e cultural em que ele está inserido. Por outro lado, ao percorrermos os estudos sobre a adolescência, percebemos que os mais diversos autores apontam como característica principal da adolescência, a formação da identidade. Pensemos melhor sobre tal ideia.

\section{A Formação da Identidade na Adolescência: Pos- sibilidade de Definição do Eu?}

Muitos autores se referem à construção da identidade como um marco característico da adolescência. Mas será mesmo que podemos dizer que a identidade é formada nessa etapa do desenvolvimento? Ou ela seria construída no decorrer de toda a nossa vida?

Ferreira, Farias \& Silvares (2003) apontam que a construção da identidade pessoal é considerada a tarefa mais significativa da adolescência: ela marcaria a transformação do adolescente em um adulto produtivo e maduro. Gallatin (1986), refletindo sobre alguns teóricos da adolescência, observa que Erikson (1968/1987) menciona que a adolescência seria um período crucial para a construção da identidade, visto que nesse período o indivíduo pode localizar o seu verdadeiro ego no tempo e no espaço, reconhecendo o passado singular que possuiu e visualizando um futuro pessoal para si próprio. Para Dutra (2000), seria difícil não reconhecer que a identidade do adolescente já vem sendo construída desde a infância, o que torna claro que a adolescência refletiria tanto o período anterior como as novas mudanças ocorridas nesse momento de vida.

Erikson (1968/1987) define identidade como "um sentimento subjetivo de uma envigorante uniformidade e continuidade” (p. 17). Para esse autor, a identidade não seria algo estático, ou imutável, mas sim uma continuidade. Entretanto, é na adolescência que o jovem efetua escolhas profissionais, escolhe um grupo de amigos com quem se identifica, pessoas com quem deseja se relacionar, e todos esses comportamentos favorecem a sua volta para si mesmo, tentando descobrir quais são os seus reais interesses, desejos, sonhos e verdades; enfim, tentando entender quem ele realmente é. 
Além disso, este autor afirma que falar da noção de identidade é falar de um processo que ocorre no âmago do indivíduo, mas também no centro da cultura coletiva, ou seja, seria um processo que estabelece uma identidade a partir das duas identidades: a individual e a coletiva. Tal reflexão é relevante, pois apresenta a construção da identidade a partir da interlocução de aspectos individuais do sujeito e de fatores culturais e sociais.

Além deste aspecto, Cassorla (1998) reconhece que é inegável que o adolescente é um indivíduo separado de seus pais e isso faz com que ele se encontre consigo mesmo, com as dificuldades e satisfações que essa busca determina. Nela, muitas vezes os adolescentes procuram identificação com ídolos, grupos de amizade, cultura, valores. E nesse aspecto, segundo Erikson (1968/1987), o potencial ideológico de uma sociedade fala de maneira mais forte ao adolescente, que deseja ansiosamente ser reconhecido e aceito por seus pares, por seus professores, por aqueles que o rodeiam. Com isso, é possível pensar que, em meio a tantos movimentos, o adolescente acaba por descobrir e solidificar conceitos sobre sua identidade, passando a tomá-los como seus.

\section{O Relacionamento Amoroso entre Adolescentes: 0 Ficar e o Namorar}

Sempre que lemos revistas direcionadas ao público adolescente, deparamos com um tema comum: o ficar e o namorar, ou seja, as formas de relacionamento amoroso dos jovens. Por volta dos anos 90, a mídia, os pais, os sistemas educacionais e toda a sociedade foram surpreendidos por um novo comportamento jovem em que era possível estar afetivamente ao lado de outro jovem, sem necessariamente tal envolvimento constituir um namoro. Acreditamos que esse seja um fenômeno em permanente modificação ao longo dos anos, e nisso se concentra a maior dificuldade para estudá-lo. Ao realizarmos uma pesquisa bibliográfica sobre o tema aqui citado, deparamos com pesquisas que remontam a datas de mais de 10 anos atrás.

Weingartner, John, Bonamigo \& Goidanich (1995), em pesquisa intitulada $O$ Ficar e o Namorar visto pelos adolescentes, refletem sobre a forma do relacionamento amoroso entre os jovens. Para os referidos autores, o adolescente busca, nessa etapa, não só uma identidade sexual, mas também uma identidade psicológica e um posicionamento social. Sendo assim, a aquisição de uma identidade própria seria muito importante para permitir-lhe estabelecer uma relação de intimidade com os outros.

Nessa perspectiva, Erikson (1968/1987) sugere que o amor adolescente é uma tentativa para se chegar a uma definição da própria identidade mediante a projeção de uma imagem difusa da própria pessoa numa outra, imagem que é vista, refletida e gradualmente aclarada. $\mathrm{O}$ mesmo autor aponta que, para estabelecer uma relação de intimidade com outro, o jovem tem que possuir uma auto-imagem firme e, consequentemente, uma identidade, pois sem conhecer suas próprias necessidades e vontades, uma pessoa não será capaz de admirar outra.

Weingartner et al. (1995) ressaltam que tanto o ficar como o namorar são formas de relacionamento afetivo que proporcionam modos de aproximação e contato íntimo entre os adolescentes. O ficar é entendido por eles como "um comportamento exploratório, pois permite uma constante troca de parceiros, que possibilita mais oportunidades de experimentação em várias situações e com várias pessoas" (p. 201). Os autores relacionaram tal necessidade de experimentação com o aspecto apontado por Erikson, em que os adolescentes têm a necessidade de vivenciar várias possibilidades na busca de uma identidade. Para eles, "o namoro está frequentemente presente nas projeções para o futuro, numa fase posterior, na qual o jovem sabe quem é e o que quer, tendo definido a sua identidade" (p. 202).

A partir dessas ideias, alguns questionamentos surgem acerca do relacionamento característico dos adolescentes, especialmente aqueles que, em função de alguma dessas formas de relacionamento amoroso, pensam em desistir de viver. Poderíamos interrogar se os jovens que tentam suicídio por motivos amorosos, ao fim de um relacionamento, sentiriam alguma insatisfação, uma nãorealização de si mesmos e de seus projetos, um não-reconhecimento de si enquanto ser existente, o qual poderia ser propiciado pelo amor ao outro? Seria o relacionamento amoroso o espaço em que o jovem se encontraria, se reconheceria, se afirmaria, ocupando um lugar no mundo? Poderíamos pensar se, no momento em que ele não mais possuísse esse amor, estaria entregue à solidão, ao sentimento de abandono e sua solidão somente cessaria no momento da morte? Tais questionamentos nos levam a pensar que a tentativa de suicídio pode se constituir em uma alternativa para o ser humano, no intuito de aliviar um sofrimento vivenciado como insuportável.

\section{Tentativa de Suicídio entre Adolescentes: um Modo de Ser...}

Cassorla (1991) refere que, do ponto de vista epidemiológico e psicodinâmico, as tentativas de suicídio se diferenciam dos suicídios exitosos, tendo em vista que nas tentativas os sujeitos são mais jovens e predominantemente, mulheres.

Dutra (1999) em estudo que investigava o índice de tentativa de suicídio entre jovens do Rio Grande do Norte no ano de 1997, constatou que, nesse ano, houve 244 casos de tentativa de suicídio no estado. 40,9\% dessas tentativas de suicídio foram cometidas por jovens com idades entre 17 e 23 anos, corroborando estudos realizados no Brasil, os quais revelam que os jovens apresentam uma grande incidência de ideação suicida, ratificando ainda mais a 
importância deste estudo. Segundo dados do Ministério da Saúde referentes ao ano de 2003, no Brasil, a faixa etária com maior incidência de internação por suicídio é a compreendida entre 20 e 24 anos, especialmente por pessoas do sexo masculino.

Para Sabino (1986, p. 144), "o suicídio é um ato de publicidade: publicidade do desespero”. Em relação a essa reflexão, Abasse, Oliveira, Silva \& Souza (2009) apontam que o suicídio ou a sua tentativa revelam uma dor emocional que o sujeito considera ser intolerável e com a qual acredita não ter capacidade de lidar. Jacobs (1971) conclui que um jovem é capaz de atentar contra a própria vida quando se sente totalmente abandonado, efetivamente sem qualquer esperança de alcançar um "relacionamento social significativo".

Cassorla (1991) chama a atenção para uma peculiaridade que permeia as tentativas e ideações suicidas em mulheres adolescentes que muito interessa ao nosso estudo: muitas vezes, as tentativas de suicídio estão relacionadas a razões amorosas, afetivas. Esse autor percebeu que o ato suicida geralmente ocorre após uma desilusão em relação a uma pessoa significativa, como namorado ou figura parental, que ameaça abandonar a jovem ou que ela sente que irá abandoná-la. Para ele, os estudos de vínculos afetivos dessas jovens, em que a ruptura ou ameaça da ruptura do vínculo leva ao ato suicida, fornecem uma pista: a de que essa relação é de tal intensidade constituída que os limites do self se confundem, de modo que a pessoa não sabe mais onde começam e onde terminam os próprios desejos e fantasias e onde começam os do outro. Percebe-se, então, uma formação de relação simbiótica; assim, a perda do parceiro é sentida como perda de parte de si mesma, onde estavam projetados muitos aspectos idealizados.

Dias (1991b) também realiza reflexões sobre o suicídio amoroso. Para essa autora, o indivíduo, muitas vezes, atribui a responsabilidade de seu ato ao outro parceiro ou, até mesmo, dedica a sua tentativa de auto-extermínio a esse outro ser. Essa autora considera que aquele que tenta suicídio em situação de abandono se mata ansiando matar o outro dentro de si mesmo. Caruso (1989) pensa que a separação de um casal traz a vivência da morte na sua consciência, face ao desaparecimento do outro em si mesmo. Dutra (2002), refletindo acerca da tentativa de suicídio de jovens, observou, entre os que praticam esse ato, que havia, em cada um deles, uma falta de amor e busca de um outro; necessidade de ser amado e de se sentir aceito, percebidos em seus relato da experiência de quase morrer.

Tais estudos e idéias nos levam a pensar na tentativa de suicídio, na escolha por não mais viver, como um (des) amor a si, uma falta de amor a seus projetos de vida, seus sonhos, uma falta de amor ao que se é e à própria vida. Um amor que, na relação amorosa, se expressa num reconhecimento de si através do outro, e que propicia ao jovem se perceber como pessoa existente e um ser de po- tencialidades. Ao perder o outro, ou na ameaça de perda desse outro no qual ele se reconhece, o adolescente perde um pouco de si, do que é, e como foi dito anteriormente, é lançado na solidão que lhe é inerente, lançado num mundo em que é responsável pelo que é, pela sua vida e seu destino.

O que faria, então, com que adolescentes que vivenciam uma situação como a descrita nestas linhas cogitem abrir mão de sua existência? Para nós, inicialmente, tal escolha estaria perpassada por toda uma concepção de si mesmo, ou seja, de um autoconceito que permearia a forma como o indivíduo se relaciona com o mundo e com as pessoas que o rodeiam.

\section{A Noção de Self em Carl Rogers: um Conceito de Si mesmo}

A definição do termo "self" ou "conceito de si mesmo" é um construto, uma elaboração eminentemente fenomenológica, em que o conceito de si mesmo ou o si mesmo como objeto percebido dentro do campo perceptual, é o conjunto de percepções ou imagens relativas a nós mesmos. Consiste numa configuração organizada das percepções que o indivíduo tem de si mesmo e que são admissíveis à consciência, enfim, as percepções e conceitos que ele possui de si mesmo em relação aos demais e ao meio.

Assim, na medida em que vão ocorrendo experiências na vida do indivíduo, estas podem, segundo Rogers (1942/1975), caso sejam percebidas como relacionadas ao self, ser simbolizadas e organizadas no autoconceito, assim como podem ser ignoradas, por não se relacionarem ao autoconceito do sujeito; assim como também podem igualmente ser recusadas, não sendo simbolizadas pelo sujeito, ou até mesmo ser simbolizadas de forma distorcida, por serem vividas como incoerentes com a imagem que o sujeito possui de si mesmo.

Com isso, o self funcionaria como um regulador do comportamento, porque teria capacidade de orientar as ações do indivíduo e de influenciar, ou mesmo determinar, como afirma Rogers (1942/1975), a maneira como o sujeito se relacionaria com o mundo que o cerca.

É importante lembrarmos que não só o self tem um componente regulador do comportamento; existe outra instância que juntamente ao self é determinante do comportamento, a tendência atualizante. Esta, busca a conservação e o enriquecimento do eu e, para isso, se oporia a tudo o que viesse a ameaçá-lo. Rogers \& Kinget (1969/1977) refletem que "todo organismo é movido por uma tendência inerente para desenvolver todas as suas potencialidades e para desenvolvê-las de maneira a favorecer sua conservação e seu enriquecimento" (p. 159). O que percebemos é que o sucesso dessa capacidade inerente do ser humano se dá em função da forma como o sujeito percebe a situação e como interpretará tal percepção 
sobre o fato vivido, o que está diretamente relacionado ao conceito que o sujeito tem de si.

As idéias apresentadas até aqui nos levam a pensar sobre a formação do conceito de si mesmo entre adolescentes que tentam suicídio por questões amorosas. Percebemos, ao longo deste percurso teórico, que muitos adolescentes, na relação amorosa, buscam no outro amado uma forma de se perceberem, de se definirem, de encontrarem seu papel no mundo. De certa forma, como vimos na noção rogeriana, o modo como os outros nos percebem influencia o modo como vamos nos perceber. $\mathrm{O}$ adolescente, ao sentir que o outro a quem ama, o qual o ajuda a visualizar a maneira como ele se percebe no mundo, passa a não mais amá-lo, fica imerso em um universo de questões que dizem respeito à maneira como ele se percebe $\mathrm{e}$ se conceitua. Podemos pensar também que o outro que nos ama nos diz que somos especiais, que somos admiráveis, que temos coisas boas a serem amadas. Ressaltam nossos atributos e, sim, dizem muito de nós mesmos, no momento em que sua fala, seu olhar, permitem nos vermos aclarados nesses gestos.

Podemos pensar que a tentativa de suicídio, como forma de comunicação, seria uma maneira de o indivíduo dizer para o outro ou para si próprio, que é difícil suportar essa perda, esse sofrimento. Mas tal experiência, por si só, não é capaz de definir tal escolha, pois ela está permeada por toda uma construção de vivências que possibilitaram uma visão positiva ou negativa de si mesmo. E isso, sim, seria o fator primordial para determinar e reger a maneira como o indivíduo, no caso, o adolescente, vai experienciar e, até mesmo significar, a perda de um amor, o rompimento de uma relação amorosa.

Muito embora a tentativa de suicídio seja interpretada como um ato extremo, final, ela pode ser entendida, nesse contexto, como uma expressão de um modo de ser, uma forma de existir. Nesse sentido, compreender a história de vida desse indivíduo pode nos fazer entender que morrer pode ser uma escolha para potencializar o existir, e que representaria continuar a viver, ainda que apenas na lembrança dos outros.

\section{Caminhos e Procedimentos Metodológicos}

A metodologia adotada por nós inspira-se numa perspectiva humanista-existencial, utilizando como instrumento de pesquisa a narrativa, de acordo com o pensamento de Walter Benjamim (1994) e com a sistematização de Schmidt (1990) e Dutra (2002).

Dutra (2002), refletindo acerca da narrativa, afirma que, na medida em que o narrador conta a sua história, a experiência se desvela, sendo construída e reconstruída através da linguagem. Para esta autora ao contar a sua história, o narrador nos introduz em sua vida, nos sensibiliza e nos coloca como participantes de sua experiência, fazendo com que o pesquisador se torne sujeito dessa experiência.
Sendo assim, propomo-nos, nessa relação de intersubjetividades, que é o encontro entre o narrador e o ouvinte, e na nossa figura de pesquisadora, possibilitar a expressão da experiência por via da narrativa e da revelação da vivência do amor adolescente. Nesse sentido, a narrativa configura uma colcha de retalhos em que os tecidos são os processos vividos ao longo da vida, tecidas no ato de narrar, de falar sobre o próprio viver. Narrar, antes de contar uma história vivida, é poder ressignificá-la, vivêla de outra maneira.

Participaram do presente estudo quatro jovens (três do sexo feminino e um do sexo masculino), que tentaram suicídio devido a questões amorosas, durante a adolescência, ou seja, quando tinham entre 12 e 18 anos.

Foram coletados dados no CIT (Centro de Informação Toxicológica de Natal-RN), o qual registra casos de tentativa de suicídio na cidade, tendo, inclusive, verificado que algumas ocorrências registradas em seus arquivos foram motivadas por questões amorosas. Sendo assim, alguns adolescentes indicados por tal órgão foram contatados e convidados para participarem da presente pesquisa. Outros jovens foram indicados por pessoas que conheciam adolescentes que haviam vivenciado uma experiência de tentativa de suicídio. Lembramos que a participação dos jovens se deu de maneira voluntária - eles aceitaram participar da pesquisa de forma espontânea - e salientamos também que todos tiveram a sua identidade preservada na análise dos dados.

Foram realizadas entrevistas semi-abertas, nas quais, após a pesquisadora estabelecer uma comunicação aberta e confortável com o jovem, lançou uma pergunta disparadora que permitiu ao jovem expressar a sua experiência de tentar desistir de viver - "Me fale sobre a sua experiência de tentar não mais viver...”. As entrevistas foram gravadas em fitas cassete, transcritas e, posteriormente, literalizadas em forma de narrativa. Reforçamos que os participantes da pesquisa assinaram o Termo de Consentimento Livre e Esclarecido. A compreensão das narrativas teve como base os sentidos que emergiram das falas dos jovens bem como os momentos que nos afetaram, indicando o sentido da experiência da desistência de viver e a experiência da relação amorosa do entrevistado. Lembramos aqui que esse momento foi precedido de inúmeras e cuidadosas leituras dos depoimentos obtidos, que permitiram a aproximação dos sentidos atribuídos pelos jovens à tentativa de suicídio. Tal forma de análise dos dados é semelhante à utilizada por Dutra (2002): os depoimentos são comentados e interpretados a partir dos significados revelados na experiência narrada, e compreendidos a partir do diálogo com os autores que ajudaram a compor o corpo teórico do trabalho e aqueles que investigaram a temática das tentativas de suicídio de jovens.

A literalização consiste no momento em que, após a transcrição das entrevistas, os depoimentos são transformados em texto, sendo as falas unidas de modo a per- 
mitir ao leitor a sensação de que está ouvindo o entrevistado narrar a sua história. Assim, as intervenções do entrevistador não estarão textualizadas no depoimento, mas certamente sua fala e sua presença estarão incluídas na narrativa.

Os passos de análise foram baseados nos procedimentos sugeridos por Bicudo \& Martins (1994), em que inicialmente realiza-se uma transcrição com a finalidade de familiarizar-se com o texto que expressa a experiência vivida; em seguida procedemos à marcação ou destacamento de núcleos significativos que emergiram da fala do narrador, evidenciando o fenômeno estudado e os aspectos a ele relacionados; por fim, procedeu-se à interpretação dos dados, que apontou para o entrelaçamento dos elementos, como a experiência vivida nesse encontro intersubjetivo que é a entrevista, os pressupostos do pesquisador e os marcos teóricos de referência.

A partir de tal procedimento, surgiram dez núcleos significativos:

- Impulsividade da tentativa de suicídio;

- Adolescente suicida e questões familiares;

- Tentativa de suicídio por ingestão de medicamentos;

- Sentimento de arrependimento ou culpa após tentativa de suicídio;

- Autoconceito do adolescente;

- Vivências concernentes à relação amorosa e ao outro amado;

- Presença de comportamentos depressivos;

- Gravidez durante a relação com os parceiros pelos quais tentaram suicídio;

- Multideterminação do ato suicida;

- Reflexão sobre a tentativa de suicídio como mobilizadora da ressignificação da vida.

\section{Discussão dos Dados}

No primeiro núcleo de sentido, Impulsividade da tentativa de suicídio, percebemos que, na grande maioria dos casos estudados, a tentativa de suicídio é vivenciada como algo imediato, respondendo a um sentimento de sofrimento insuportável. Alguns adolescentes revelaram, inclusive, que ela ocorreu em um momento de desespero, o que corrobora a reflexão de Cassorla (1998) de que, muitas vezes, o suicida não deseja morrer, mas sim fugir de um sofrimento insuportável. Essa mesma observação foi feita pela OMS (2000), a qual aponta como característica daquele que pensa em suicidar-se a impulsividade, que pode ser desencadeada por eventos negativos do dia-a-dia. Como ilustrado no depoimento de Mirela:

"Eu nunca tinha passado por isso na minha vida, nunca tinha pensado em morrer, nunca na minha vida. Foi um ato impulsivo."
Podemos observar como esse ato vem em resposta à vivência insuportável de um sofrimento e que o adolescente não conseguiu resolver ou elaborar de outra forma. Tal experiência soa como uma tentativa de lidar com essa dor, mesmo que ela racionalmente não seja entendida dessa maneira. Muitos a descrevem como algo que ainda não pôde ser compreendido plenamente por eles mesmos, demonstrando, inclusive, perplexidade com tal escolha.

Outro aspecto revelado nos depoimentos relacionase ao Adolescente suicida e questões familiares., face ao fato de que, Em muitos depoimentos, os jovens entrevistados eram provenientes de famílias com perdas parentais ou separação dos pais ou até mesmo em que havia ausência de diálogo, aspecto presente também em estudos como o de Cassorla (1991) e o de Dutra (2000), dentre outros. Tal reflexão pode ser exemplificada no depoimento de Pedro:

“...Minha mãe mora em Brasília, meu pai mora aqui. Então, eu morava só com meu pai, ainda moro só com meu pai. Então não existia, não existe um relacionamento entre pai e filho que possibilitasse a compreensão maior dele."

Percebemos nas falas da maioria dos entrevistados a presença de um ambiente familiar marcado pela desestruturação de seu núcleo principal, com perda de um ente querido, como o pai, ou com a separação dos pais. Em alguns dos depoimentos, observamos quanto tal ocorrência marcou a vida dos adolescentes. Cassorla (1991) verifica que a maioria dos adolescentes suicidas provém de famílias em que falta uma figura parental, ou faltam ambas, por abandono ou separação.

Percebemos nos depoimentos analisados o relato da dificuldade em conversar sobre o ato suicida, bem como em ter um espaço para dialogar sobre as ocorrências de seu dia-a-dia. Um aspecto concordante entre os entrevistados está no fato de que todos realizaram suas tentativas de suicídio ingerindo medicamentos que utilizavam cotidianamente. Três dos quatro entrevistados referiram o uso de medicação controlada para tratamento da depressão ou para outro tipo de tratamento. Estatisticamente, estudos apontam para o fato de que as tentativas de suicídio ocorrem, em sua maioria, por ingestão de medicamentos, o que torna esses suicídios fracassados, pelo baixo grau de agressividade do método escolhido.

Tal constatação sugere que é talvez devido à impulsividade do ato suicida, descrito nos depoimentos estudados, que esses jovens estão recorrendo ao método mais acessível no momento de questionamento de suas vidas. O medicamento de uso diário torna-se, então, o elixir para sanar a dor, como vemos no depoimento de Tatiana:

“...eu tomo anticonvulsivante, eu tenho epilepsia. Aí eu tava tomando gardenal, eu tinha uma cartela cheia e outra com 15 comprimidos, e as duas estavam juntas. 
Eu peguei só a que tinha 15. Eu ficava me sentindo muito só, apesar de ter muita gente dentro de casa, mas eu nunca conseguia conversar com ninguém. Aí escutei aquela voz me dizendo: 'vá a tal canto! pegue aquela cartela, tome!’”

Na fala dos entrevistados percebemos que os atos são precedidos de "gatilhos", fatos ou situações que impulsionam a desistência de viver, como uma frustração vivida. Interessante percebermos a presença de um sentimento de arrependimento ou culpa após tentativa de suicídio, como visto no depoimento de Fabiana:

"Com algum tempo a mais, cerca de três meses depois, é que eu vim, realmente, cair na real do que tinha acontecido, do que foi ter tentado suicídio, realmente suicídio, porque nos primeiros dias, primeiros momentos, eu tava completamente fora de mim, tava frágil, sensibilizada, muito carente, precisando muito da família."

Nos depoimentos analisados, observamos os conflitos vividos por um suicida, a vergonha de assumir um ato tão extremo, a maneira como tal ato mobiliza a família, mas também descontentamento por ter tentado se matar por uma outra pessoa, que não merecia a perda de sua própria existência. Do mesmo modo percebe-se a presença da culpa pelo ato a partir do momento em que outros os censuraram, quando passaram a julgá-los e a atribuir-lhes a responsabilidade pelas consequências do seu ato, o que nos remete ao processo de formação do self segundo as ideias de Rogers \& Kinget (1942/1977). Isso porque, para esses autores, no momento em que a pessoa está incongruente com a sua experiência, com seus pensamentos e sentimentos, ela passa a adotar o outro como referência, perdendo, assim, o lócus de avaliação da própria experiência, e colocando-a no outro.

No entanto, cada experiência de tentar suicídio é única e particular. Estamos falando de uma vivência que se processa de diferentes maneiras em cada sujeito. Certamente Possivelmente motivado pela forma particular como cada sujeito vivencia as experiências em sua vida a partir de seu autoconceito. Nos jovens entrevistados, percebemos a expressão de conteúdos referentes à definição de si mesmos, como visto no depoimento de Pedro:

“...eu sempre me achei a pior pessoa do mundo... nunca me senti pertencente ao grupo em que eu vivia da adolescência, que é com menino com treze/catorze anos que já perdeu a virgindade, fica com cinco meninas numa noite, etc; que você sabe que é comum."

Em vários momentos os jovens relatam a mudança da definição de si após a vivência da relação amorosa. Isto porque, percebemos vivências concernentes à rela- ção amorosa e ao outro amado, expressas numa vivência intensa em função do ser amado. Como podemos ver ainda no depoimento de Pedro:

"Eu tive um relacionamento com uma garota e eu amava ela. Então eu comecei a achar que ela era o foco da minha vida, eu comecei a colocar ela no centro da minha vida, pensando que se eu não vivesse com ela a vida não teria pra mim nenhuma outra importância. Ela tinha tudo que eu imaginava de mulher ideal pra minha vida, então eu fantasiei que só existia ela pra minha vida."

Nos depoimentos analisados percebemos um sentimento em relação ao outro vivido de maneira intensa, assim como a relação amorosa também era vivida dessa forma. O outro é referido como centro da vida do entrevistado, centro de sua atenção, o que faz com que ele atribua seus sentimentos ao outro, colocando a si mesmo em segundo plano. Tal reflexão nos faz lembrar Cassorla (1991), o qual, refletindo sobre a tentativa de suicídio amoroso entre mulheres, verificou a presença de uma relação simbiótica entre os amantes, dando a sensação de que os sentimentos e desejos são um só.

Além disso, o que percebemos em diversos momentos da fala desses jovens é que os limites do self entre cada um deles e seu (sua) namorado(a) se confundem, de maneira que eles não sabiam mais o que pertencia a eles e o que pertencia ao outro. Passaram a ser um só, ser, em que as vontades e os desejos do outro eram incorporados como se fossem seus, pertencentes ao seu autoconceito. A baixa auto-estima, uma concepção de si negativa, os fez adotar como ponto de referência a fala, a voz do outro, que passa a ser introjetada por eles como se fosse a sua real experiência. O outro que os aprecia e a quem eles amam, passa a ser o mundo real de experiências desses adolescentes, que se distanciam de si mesmos e, consequentemente, de quem eles realmente são, em função da adoção de um referencial de um outro e não do seu próprio. Toda essa reflexão, como foi dito anteriormente, nos remete a Rogers \& Kinget (1942/1977), com sua noção de inautenticidade, em que experiências, valores e ideias dos outros passam a ser incorporados como próprios, fazendo com que o sujeito se distancie de seu si mesmo. O que sugere pensar que os adolescentes aqui estudados, na maioria das vezes, agiram de forma inautêntica.

Outros componentes que surgiram nos depoimentos analisados foram referências de baixa auto-estima e a necessidade de sentir-se especial para o outro, receio de abandono do outro amado, a referência a um sentimento de obsessão para com o outro, bem como de uma idealização da concepção de amor.

Observamos nos participantes aspectos que nos permitem perceber uma história de vida marcada por separação dos pais, perda de um ente querido, falta de diálogo no ambiente familiar, eventos traumatizantes 
- como estupro -, uma educação repressora, com valores rígidos. De certa maneira, esses fatores, confluindo e em permanente interação com os acontecimentos vividos pelos sujeitos, os levaram a vivenciar a relação amorosa de maneira tão intensa. Para alguns, a relação amorosa era a possibilidade de terem uma vida diferente, um lar como sonharam, marcado por essa visão de amor romântico presente em nossa cultura. É comum encontrar na fala dos adolescentes entrevistados a menção de que eles sempre foram o que sempre sonharam. Para outros entrevistados, a relação amorosa que mantinham com o(a) namorado(a) era a tentativa de perpetuarem a que viam entre os pais, na construção de um lar, de uma família. Dentro das discussões acima referenciadas, percebemos a presença de comportamentos depressivos, como visto no depoimento de Pedro:

“...Eu ficava na cama sem comer, e minha mãe tentando me animar. Aí eu peguei cortei meu cabelo. Eu tinha o cabelo muito grande, entendeu? Eu tinha o cabelo grandão e eu cortei o cabelo do nada, coisa pra chamar a atenção mesmo. E ficava na cama, etc.”

Em pesquisa realizada por Filho, Mezzaroba, Turini, Koike, Júnior, Shibayama e Fenner (2002), com adolescentes que tentaram suicídio através da ingestão de medicamentos, os autores observaram que, em $67,1 \%$ dos casos estudados, houve referência a diagnóstico depressivo, o que, de certa maneira, corrobora observações da literatura sobre a relação entre depressão e ocorrência de suicídio.

Outro interessante aspecto observado entre as entrevistadas foi a presença de gravidez durante a relação com os parceiros pelos quais tentaram suicídio. $\mathrm{Na}$ apreciação das entrevistas, observou-se também que as três entrevistadas engravidaram dos parceiros com quem estavam durante a tentativa de suicídio. Cassorla (1991) observou, em seu estudo com mulheres que haviam tentado suicídio, ser comum a referência de gravidez neste período ou após a ocorrência do mesmo, possivelmente em função de uma tentativa de reestabelecer a relação simbiótica da qual falamos anteriormente.

Tais componentes observados nas narrativas dos jovens reforçam a reflexão da multideterminação do ato suicida. Nas entrevistas realizadas, apesar de estarmos estudando a relação entre tentativa de suicídio de adolescentes e questões amorosas, vimos que não é apenas esse fator que determina a tentativa de suicídio em si, mas a interação dos mais diversos aspectos que integram a vida do sujeito. Ressaltamos a importância de não buscarmos compreender a tentativa de suicídio a partir de fatos isolados, visto que esse é um fenômeno multideterminado: como vimos, vários fatores interagem para fazer com que um jovem pense em desistir de sua vida. Tais fatores influenciam na maneira como o jovem se relaciona com o mundo e com as pessoas ao seu redor. Isso também pode influenciar a maneira como eles se posicionam diante de um outro no contexto da relação amorosa. Sabemos que todas as experiências vividas pelo adolescente e pelo ser humano, desde a sua infância, contribuem para a formação do seu autoconceito. Dependendo da maneira como essas experiências são internalizadas, são significadas pelo homem, elas vão favorecer uma noção de si mesmo realista ou não. Ee exatamente isso que vai determinar a maneira como o ser humano e por que não dizer, o adolescente, vai se posicionar, se perceber na interação com os outros viventes do seu mundo.

Neste sentido, os depoimentos revelaram ainda uma reflexão sobre a tentativa de suicídio como algo mobilizador da ressignificação da vida. Percebemos um papel reconstrutor que a experiência de entrar em contato com a finitude teve para esses jovens. Todos os quatro entrevistados relataram uma certa ressignificação de seu viver após a tentativa de suicídio. E isso se torna relevante quando retomamos a fala de Cassorla (1991), o qual relata que existem indícios de que, em alguns casos, a tentativa de suicídio entre adolescentes pode ser considerada como um fator estruturante da personalidade, visto que seria uma tentativa do ego de apelar para o meio ambiente, como um pedido de ajuda. Como percebemos no depoimento de Mirela:

"E depois de tudo, eu... eu acho que eu mudei de pensamento, de cérebro, o meu se transformou: aquela Mirela imatura, aquela Mirela que achava que o mundo era um mundo de fantasias, sabe? Que a gente, as pessoas eram maravilhosas, e todo mundo era, sabe? E a gente não deveria desconfiar de ninguém, porque todo mundo é mil maravilhas, mudou completamente. Mudou, mudou totalmente."

Alguns entrevistados expressam uma ressignificação de sua vida, passando a se perceber de uma maneira diferente, reavaliando a vida e o seu viver.

\section{Considerações Finais}

Revendo as entrevistas e depoimentos, bem como relendo a literatura estudada, constatamos a complexidade da temática aqui abordada. Devemos, por isso, sempre ter o cuidado de não tentar ver relações de causalidade entre os fatos, buscando explicações para a tentativa de suicídio, pois, se assim o fizermos, corremos o risco de chegar a conclusões equivocadas.

Ao invés disso, devemos tentar compreender cada caso como particular, único, e só podendo ser entendido a partir da história de vida do sujeito, do seu contexto de vida, dos aspectos culturais e sociais com os quais ele está envolvido.

Nas quatro entrevistas que compuseram o nosso quadro de análises, vários fatores, integrados, favorece- 
ram a compreensão das tentativas de suicídio, embora o nosso foco estivesse direcionado, primordialmente, aos motivos amorosos de tentativas de suicídio adolescente. Entendemos que as demais situações de vida do sujeito influenciavam a maneira como eles se posicionavam em relação a temas como o amor, a percepção do outro amado e, principalmente, o que esperar de uma relação amorosa. Percebemos quanto o contexto familiar, a educação, os valores cultivados socialmente, os aspectos culturais de nossa sociedade influenciaram a maneira como os adolescentes de nossa pesquisa se percebiam. Encontramos em seus discursos palavras que refletiam o mito do amor romântico, com base no qual o indivíduo espera por alguém a quem ama e que o amará com a mesma intensidade, assim como nutre expectativas de encontrar um par perfeito, alguém com quem constituir família, ter filhos, ter um lar, perpetuando, muitas vezes, a história de sua própria família.

Observamos também nesses jovens a presença de baixa auto-estima, com referências negativas de si mesmos, visões distorcidas de si. Muitas vezes o indivíduo não possuía o conceito real de si mesmo, adotando discursos de outro e culpando o outro amado pela sua infelicidade, sem se implicar na relação amorosa. E isso está em total consonância com a reflexão sobre self de Carl Rogers que utilizamos neste trabalho, de que esses jovens passaram a adotar o outro amado como referência, afastando-se da capacidade de se auto-avaliar e se autocorrigir, as quais seriam capacidades que favoreceriam a congruente experiência e o crescimento. E como bem referenciamos em nosso título, tais fatores evidenciaram não só um desamor a si, presentes nas referências negativas atribuídas a si mesmo, como também foram presentificadas a partir do desamor do outro a eles mesmos, ou seja, quando o outro a quem amavam passa a não desejá-los mais ou a dar a percepção de que não mais o querem.

O nosso propósito, ao final do trabalho, é que as reflexões desenvolvidas aqui possam ser compartilhadas com profissionais de saúde e a sociedade, de uma maneira geral, através de eventos científicos, publicações e quaisquer meios de comunicação que venham a contribuir para confirmar a função social de um trabalho científico.

\section{Referências}

Abasse, M. L. F., Oliveira, R. C., Silva, T. C. \& Souza, E. R. (2009). Análise epidemiológica da morbimortalidade por suicídio entre adolescentes em Minas Gerais, Ciência \& Saúde Coletiva, 1 (2), 407-416.

Bicudo, M. A.V. \& Martins, J. (1994). A pesquisa qualitativa em Psicologia. Fundamentos e Recursos Básicos. São Paulo: Editora Moraes.

Caruso, I. (1989). A separação dos amantes. São Paulo: Diadorim Cortez.
Cassorla, R. M. S. (1991). Do Suicídio: Estudos Brasileiros. São Paulo: Papirus.

Cassorla, R. M. S. (1998). O suicídio - reavaliando um clássico da literatura sociológica do século XIX. Cadernos de Saúde Pública, 14 (2), 07-34.

Dias. M. L. (1991). Suicídio, testemunhos de adeus. São Paulo: Editora Brasiliense.

Dutra, E. (1997). Estudo epidemiológico do suicídio no Rio Grande do Norte: 1985/1996. Anais da VI Semana de Humanidades [p. 241]. Natal: EDUFRN.

Dutra, E.M. (1999). Epidemiologia das tentativas de suicídio no Rio Grande do Norte. Relatório de Pesquisa não-publicado. Universidade Federal do Rio Grande do Norte, Natal, Rio Grande do Norte.

Dutra, E. M. S. (2000). Compreensão de tentativas de suicídio de jovens sob o Enfoque da Abordagem Centrada na Pessoa. Tese de Doutorado não-publicada. Universidade de São Paulo, São Paulo.

Dutra, E. M. S. (2002). A narrativa como uma técnica de pesquisa fenomenológica. Estudos de Psicologia, 7 (2), 371-378.

Erikson, E. (1987). Identidade, Juventude e Crise. Rio de Janeiro: Editora Guanabara (Original publicado em 1968).

Ferreira, T. H. S.; Farias, M. A. \& Silvares, E. F. M. (2003). A construção da identidade em adolescentes: um estudo exploratório. Estudos de Psicologia (Natal), 8 (1): 107-115

Gallatin, J. (1986). Adolescência e individualidade: Uma abordagem conceitual da Psicologia da Adolescência. São Paulo: Editora Harbra.

Jacobs, J. (1971). Adolescent suicide. New York: Wiley.

Mustelier, L. I. (2005) ¿Adolescentes Problemas o Problemas de la Adolescencia?, Monografia não publicada, [citado em 10 abril 2005], disponível em World Wide Web: http://www. monografias.com/trabajos13/adopro/adopro.shtml\#sui.

OMS (2000). Prevenção do suicídio: um manual para profissionais da saúde em atenção primária. Transtornos Mentais e comporta mentais. Departamento de Saúde Mental. p. 1-22. [Citado em 20 de Junho de 2006] Disponível em World Wide Web: http://www.who.int/mental_health/prevention/suicide/en/suicideprev_phc_port.pdf

Palácios, J. (1995). O que é adolescência? Em C. Coll; Palácios, \& A. Marchesi (Orgs.). Desenvolvimento Psicológico e Educação (Vol.1 - Psicologia Evolutiva) [p. 263-272]. Porto Alegre: Artes Médicas.

Rogers, C. R (1975). Terapia Centrada no Paciente. São Paulo: Martins Fontes (Original publicado em 1942).

Rogers, C. R. \& Kinget, M. G. (1977). Psicoterapia e Relações Humanas: Teoria e prática da terapia não-diretiva. Belo Horizonte: Interlivros (Original publicado em 1969).

Sabino, F. (1986). Suíte ovalliana. In Fernando Sabino, As melhores crônicas de Fernando Sabino [pp. 139-145]. Rio de Janeiro: Record. 
Schmidt, M. L. S. (1990). A experiência de psicólogas na comunicação de massa. Tese de doutorado não-publicada, Instituto de Psicologia da Universidade de São Paulo, São Paulo.

Souza, E. R.; Minayo, M. C. D. S. \& Malaquias, J. V. (2002) Suicide among Young people in selected Brazilian State capitals. Cadernos de Saúde Pública, 18 (3), 673-683.

Weingartner, C. L.; John, D.; Bonamigo, L. D. R. \& Goidanich, M. (1995). O Ficar e o Namorar visto pelos Adolescentes. Psicologia: Reflexão e Crítica, 8 (2): 181-203.
Ana Karina Silva Azevedo - Psicóloga, Doutoranda em Psicologia no PPgPsi da Universidade Federal do Rio Grande do Norte (UFRN) e Professora Assistente da Universidade Federal do Rio Grande do Norte (Campus Facisa). E-mail: anakarinaazevedo@hotmail.com

Elza Maria do Socorro Dutra - Doutora pela Universidade de São Paulo (USP). Psicóloga e Docente do PPgPsi da Universidade Federal do Rio Grande do Norte (UFRN). Endereço Institucional: Universidade Federal do Rio Grande do Norte, Centro de Ciências Humanas Letras e Artes, Programa de Pós-graduação em Psicologia. Campus Universitário, s/n (Lagoa Nova). CEP 59075-970, Natal/RN. E-mail: elzadutra.rn@gmail.com

Recebido em 09.12.11

Aceito em 10.05.12 